\title{
Rational and Adaptive Performance Expectations in a Customer Satisfaction Framework
}

\author{
MICHAEL D. JOHNSON \\ EUGENE W. ANDERSON \\ CLAES FORNELL*
}

\begin{abstract}
This article develops and tests alternative models of market-level expectations, perceived product performance, and customer satisfaction. Market performance expectations are argued to be largely rational in nature yet adaptive to changing market conditions. Customer satisfaction is conceptualized as a cumulative construct that is affected by market expectations and performance perceptions in any given period and is affected by past satisfaction from period to period. An empirical study that supports adaptive market expectations and stable market satisfaction using data from the Swedish Customer Satisfaction Barometer is reported.
\end{abstract}

$\mathrm{T}$ here is an extensive and growing body of research on customer satisfaction that focuses primarily on disaggregate or individual-level satisfaction with particular goods or services (Yi 1991). Relatively little attention has been paid to the determinants of marketlevel satisfaction, which is defined here as the aggregate satisfaction of those who purchase and consume a particular product offering (e.g., Ford Escort owners or Federal Express users). Our goal is to develop and test an approach to modeling satisfaction that links marketlevel expectations, perceived performance or value, and customer satisfaction over time. In the process we address two important questions: (1) What is the nature of market-level product and service performance expectations? and (2) What are the antecedents of marketlevel satisfaction? Our discussion suggests that while there is a large rational component to market expectations, they remain adaptive to changing market conditions. Satisfaction in any given period should also be a function of perceived performance, expectations, and prior satisfaction such that, from year to year, market satisfaction is relatively stable.

*Michael D. Johnson and Eugene W. Anderson are associate professors of marketing, and Claes Fornell is the Donald C. Cook Professor of Business Administration and director of the National Quality Research Center, School of Business Administration, University of Michigan, Ann Arbor, MI 48109-1234. The authors gratefully acknowledge the financial support of the National Quality Research Center, the School of Business Administration at the University of Michigan, and Sweden Post. We also thank the past and current editors, the associate editor, and the three reviewers for their constructive comments on earlier versions of this article.
There are both scientific and pragmatic reasons for studying market-level customer satisfaction and its antecedents. From a scientific standpoint, satisfaction research stands to gain by augmenting existing individual-level studies with market-level analyses. Studying customers in the aggregate is one way to establish empirical generalizations in the domain of satisfaction research. While individual-level studies demonstrate the range of possible behavioral phenomena, psychologists have long recognized the difficulties involved in obtaining generalizations from them (Wärneryd 1988). A lack of emerging empirical generalizability is clearly evident in the quality and satisfaction literature, in which the debate over alternative models and methods continues (Anderson and Sullivan 1993; Yi 1991). It can be argued that the attitudes and behavior of individuals may be so situationally unique that individuallevel studies will be unable to establish reliable generalizations in this area. One solution is the aggregation of individuals, occasions, stimuli, and/or modes of measurement (Epstein 1980). This aggregation serves both to reduce error in the measurement of key satisfaction-related variables and to increase the establishment of coherent relationships with other variables (e.g., purchase intentions or customer loyalty).

There is ample evidence of the value gained by augmenting the traditional focus in psychological studies on individual behaviors or events with aggregates. For example, personality characteristics that have little or no effect on individual behaviors show statistically significant and predictable relationships to behavioral aggregates (Epstein 1979, 1980). In research on the "cross 
section versus time series paradox" (see Wärneryd 1988), individual data often show no relationship between consumer attitudes toward economic conditions and subsequent purchase behavior. This attitude-behavior relationship is, however, clear and robust in aggregate data.

From a pragmatic standpoint, while service providers may focus on tailoring their offerings to an individual, marketing managers, product planners, and development teams focus on the needs and wants of entire markets or market segments. Aggregate-level surveys, from J. D. Power surveys of automobile owners, to hotel surveys of recent guests, to Consumer Reports surveys of movie-going readers, provide important indicators of the level of satisfaction in a firm's customer base. This market-level satisfaction is a strong indicator of aggregate customer retention and future profitability (Anderson, Fornell, and Lehmann 1994) and thus has emerged as an important yardstick or benchmark for firms seeking to accelerate business performance as well as for policymakers interested in tracking consumer well-being.

In order to develop our model of market-level satisfaction, we begin by describing various expectation models that have been developed in a price context and discuss their applicability to market performance information. We then develop a satisfaction model in which customer satisfaction is a function of customers' expectations, perceptions of performance, and prior satisfaction. We develop and compare alternative specifications using market-level data from the Swedish Customer Satisfaction Barometer (SCSB; Fornell 1992). Our results suggest that market performance expectations have a large rational component yet remain adaptive to changing market conditions. Market-level satisfaction is also relatively stable over time and is positively affected by performance and expectations in any given period.

\section{MARKET-LEVEL EXPECTATIONS}

\section{Price Expectation Models}

Modeling market-level satisfaction requires an understanding of market-level product and service performance expectations. Although performance, in this context, includes both price and nonprice performance information, there is a vast literature on alternative price expectation models in economics, economic psychology, and consumer behavior on which to draw (Lovell 1986; Oliver and Winer 1987). After reviewing the various expectation models, we discuss their applicability to market-level perceptions of product performance. More detailed discussions of the various expectation models are provided elsewhere (Glazer, Steckel, and Winer 1988, 1990; Johnson and Plott 1989; Oliver and Winer 1987; Vanden Abeele 1988).

The traditional "cobweb" model (see, e.g., Mansfield 1975) views price expectations simply as equivalent to the observed market price in the immediately preceding period. That is,

$$
E_{t}=P_{t-1}
$$

where $E_{t}$ is expected price in time period $t$, and $P_{t-1}$ is the observed market price in time period $t-1$. The overly adaptive or "biased" nature of this model led Goodwin (1947) to introduce an extrapolative price expectations model in which price is expected to change by some constant factor times the most recently observed change in price. Goodwin's (1947) model can be stated as follows:

$$
E_{t}-P_{t-1}=-p\left(P_{t-1}-P_{t-2}\right),
$$

where $-p$ is the "extrapolative coefficient of expectation," and price expectations are essentially a weighted average of prices over the past two market periods. This model is also relatively biased, however, in that expectations ignore all but the previous two periods of price information.

More recently, researchers have focused on adaptive expectations (Nerlove 1958) that stem from Hicks's (1939) concept of the "elasticity of expectations." According to the adaptive model, current price expectations are a weighted average of prior expectations and the most recently observed price information:

$$
E_{t}=(1-b) E_{t-1}+b P_{t-1},
$$

where $b$ is a coefficient of adaptation such that $0<b$ $<1$. The greater this coefficient of adaptation, the more significant the effect of immediate past price information on current expectations, or the more adaptive the expectations. In a customer satisfaction context, this model would view current product performance expectations as a weighted average of prior customer expectations and the most recently observed level of performance. As for price, the more weight placed on the recent performance information, the more adaptive the expectations.

An important feature of the adaptive expectations model is that it provides a psychologically attractive view of expectation formation. Buyers hold an ongoing expectation of performance that is adjusted on the basis of currently available information (Winer 1985). Adaptive expectations are thus consistent with the anchoring and adjustment-type processes often found in information-processing models (Tversky and Kahneman 1974).

A potential problem with all of the preceding expectation models is that, from an economic perspective, they are biased toward more recent price information. In a stable market, any bias would result in systematic forecasting errors and profitable opportunities for more accurate forecasts so that the bias is eliminated over time. This consideration led Muth (1961) to propose an economic framework of rational expectations. Accordingly, economic agents use all relevant information such that the observed price is equal to the mean ex- 
pectation of buyers in a market (e.g., the market price expectation), which, in turn, is the same as that predicted by the relevant economic theory. That is,

$$
P_{t}=E_{t}=P_{t}^{*}
$$

where $P_{t}^{*}$ is the equilibrium price in time period $t$. Cyert and DeGroot (1974) view rational expectations as a general process of Bayesian revision. Learning is continually taking place in the market, and priors are updated as information is accumulated over time. Unlike adaptive expectations, rational expectations presume a stable or mature market that is not undergoing any fundamental changes. Therefore, according to rational expectations, $b$ in the adaptive expectations model (Eq. 3) should be insignificant in the context of stable and mature markets; prior expectations should completely describe current expectations.

Although consumer research and marketing studies have examined and modeled the nature of price expectations, the focus has been on disaggregate expectations. Winer (1986) developed a brand choice model for frequently purchased products that incorporates a reference price expectation. Using panel data from a sample of frequent purchases of three brands of coffee, Winer (1986) found that an extrapolative expectations version of the model and a rational expectations version fit the data equally well. In a study similar to Winer's, Kalwani et al. (1990) developed a two-stage disaggregate choice model in which the first stage uses rational expectations to determine how expected prices are formed. Also using scanner panel data for ground coffee, they obtained results that suggest that adding expectations as a mediating construct improves the ability of brand choice models to explain choice behavior.

Jacobson and Obermiller (1990) focused directly on the nature of consumers' expected future prices through the use of grocery store data on canned tuna sales. Their results revealed consumer forecasts that were both biased and inefficient in an economic sense and more consistent with a serial correlation model. In a slightly different context, Glazer et al. $(1988,1990)$ used the rational and adaptive expectations models to study the expectations that managers form in a simulated competitive marketing environment. They found partial support for the rational expectations hypothesis. While their managers' expectations were relatively efficient, or made use of the available relevant information, they were biased. These studies support Lovell's (1986) contention that rational expectations do not completely describe individual-level expectations.

\section{Market Performance Expectations}

The nature of market performance expectations has not, to our knowledge, been studied in a customer satisfaction context. To generalize from existing price research and models to market-level performance expectations, we must address two key considerations: (1) the effect of aggregation on the nature of expectations and (2) the effect of nonprice information on the nature of expectations.

With regard to the effects of aggregation, the price research is clear in suggesting that market expectations are more "rational" or accurate than are individual expectations. That is, different expectation models often explain individual and aggregate behavior, at least in those cases where markets are stable or at a relatively mature stage in their life cycle. In general, while the rational expectations model is evoked to explain the stability of aggregate market behavior, the adaptive expectations model is typically better at describing the behavior of individuals (Johnson and Plott 1989; Lovell 1986; Oliver and Winer 1987). While the informationprocessing requirements of rational expectations are rather extreme when applied to individuals, who have inherent processing limitations, adaptive expectations are more consistent with the individual psychological process of anchoring and adjusting. Different individuals anchor, or focus, on different information in their environment. Individuals are moody, have prejudices, and are often badly informed. They are also "constantly perceiving, forgetting, or ignoring selectively" (Strumpel 1979 , p. 54). For example, in a study of price expectation processes, Della Bitta and Monroe (1974) found that the presentation of extreme prices early in a series serves to anchor price perceptions toward the extreme. Monroe, Della Bitta, and Downey (1977) found evidence of other contextual effects on price expectations, such as the intended use or purpose of the purchase. The point is that individual expectations may change quickly and be very adaptive to current information.

In contrast, aggregate expectations change more slowly and are subject to much less variation over time (Katona 1980). Just when this aggregation effect exists should depend on the distribution of individual anchors and adjustments. When these individual differences are randomly distributed around performance, as one might expect in a very stable market, expectations that are individually adaptive should aggregate into a rational market-level expectation. This is why Katona (1980) argues that "many factors cancel out when the attitudes and behavior of very large groups are compared" ( $p$. 60 ). Individual differences in pessimism or optimism, for example, tend to wash out in the aggregate, making market-level expectations far more stable than those of individuals. Similarly, Van Raaij (1989) argues that, while rational expectations are not likely to describe the process of individual-level expectation formation, they may be very useful in describing macro- or aggregate-level expectations. This aggregation effect is consistent with Muth's (1961) original arguments and the view that economic models such as rational expectations do not claim to describe the process by which people actually make decisions. Rather, they claim to explain why certain behavior and decisions persist at a market level. 
Two studies, one involving firms and one involving individuals, illustrate this phenomenon of aggregate rationality. Hirsch and Lovell (1969) found evidence of bias in the sales expectations of firms, whereby some firms were perpetual optimists who regularly overestimated and others were perpetual pessimists who regularly underestimated future sales. However, the bias in the optimists effectively canceled out the bias in the pessimists such that the aggregate industry expectations were rational. Johnson and Plott (1989) studied individuals competing in four experimental markets to test the stability of supply-response lag markets and examine the nature of individual and aggregate price expectations. Across the markets, adaptive expectations provided the best explanation of individual price expectations, followed by extrapolative expectations. Rational expectations provided a poor description of the individual-level expectations, a result that is consistent with individual-level experimental (Williams 1987), consumer panel (Jacobson and Obermiller 1990), and survey research (Lovell 1986). However, contrary to the equilibrium predictions of the adaptive and extrapolative expectations models, all four markets were stable. The aggregate behavior in these markets was more consistent with the rational expectations hypothesis. This mirrors other accumulated findings in experimental economics in which apparently anomalous individuallevel data are far more rational and consistent with economic theory in the aggregate (Plott 1986).

Yet this aggregation effect assumes that the informational anchors and biases of individuals are randomly distributed, as might be approximated in a stable market. The markets studied by Johnson and Plott (1989), for example, were stable in that supply and demand conditions remained constant over those market periods in which expectations were examined. If individual-level biases are more systematic and are being driven by some fundamental change in market conditions, such as a market that is in a period of growth, decline, quality improvement, or deregulation, then aggregate expectations should also be somewhat adaptive. If markets are continuously improving, and this improvement is reflected in a firm's product mix, then the market as a whole should update its expectation and learn in times of change. As Simon (1979) argues, there is no reason to assume that the same expectation function will describe aggregate expectations in different contexts or in the same context at different points in time.

The second major issue to address is the extrapolation from price to performance expectations, where performance includes both price and nonprice information. Performance information is fundamentally different from price alone. Nelson (1970), for example, distinguishes between search and experience attributes. Search attributes are, like price, readily observable prior to purchase. Experience attributes are those qualities that can be evaluated only after purchasing and consuming the product. Darby and Karni (1973) subsequently identified a third category they call credence attributes, which includes those attributes that are not readily observable even after some degree of purchase and consumption (e.g., the longevity of an appliance). Basically, price information is immediately observable, while quality information is not. Because quality perceptions emerge over time, market adaptation to a change in performance or quality should be more prolonged than adaptation to a change in price.

Taken together, these arguments support the following proposition: Market-level performance expectations should be largely rational as a result of the effects of aggregation, yet they should remain somewhat adaptive in the face of changing market conditions. In an age of customer satisfaction, quality improvement, and total quality management programs, many markets are changing, and consumers are adapting to the changing quality levels. The American automobile industry is a case in point, where prior negative experiences resulted, over time, in low expectations. Although objective quality improvements were well documented, it has taken buyers some time to learn about these improvements through their own experiences and to adapt their expectations accordingly.

"Changing market conditions" aptly describes the situation faced by those firms in the Swedish Customer Satisfaction Barometer (SCSB). The SCSB was established to provide benchmarks and help improve the competitiveness of Swedish goods and services (Fornell 1992). As economic unity spreads across Europe, Swedish firms and industries are facing increasing competition across the board and are trying to improve quality to defend themselves. Therefore, while we expect that market performance expectations in Sweden are relatively stable or rational, some significant market adaptation effects should persist in times of change.

Because aggregate expectations should be relatively accurate or consistent with perceived performance, one could argue that a separate expectations construct is unnecessary. Conceptually, however, the constructs capture different sources of important information. Perceived product performance or quality captures information about current customers' more recent experiences with a good or service, while expectations reflect customers' accumulated experience and forecast of future quality experiences. As noted, expectations may be adapting to a changing performance environment and have their own positive effect on satisfaction. Even under a hypothesis of purely rational expectations, random shocks, or changes in performance due to unpredictable environmental factors, will prevent expectations and performance from being equal at any given point in time (Pashigian 1970). 


\section{MARKET-LEVEL SATISFACTION}

\section{Two Conceptualizations of Customer Satisfaction}

The modeling of customer satisfaction depends critically on how satisfaction is conceptualized. Two general conceptualizations of satisfaction exist in the literature, transaction-specific satisfaction and cumulative satisfaction (Anderson and Fornell 1993; Boulding et al. 1993). Consumer and marketing researchers are often concerned with satisfaction as an individual, transaction-specific measure or evaluation of a particular product or service experience (Cronin and Taylor 1992). There is disagreement, however, as to whether perceived service quality is an antecedent to transaction-specific satisfaction (Parasuraman, Zeithaml, and Berry 1988) or transaction-specific satisfaction is an antecedent to perceived service quality (Bitner 1990; Bolton and Drew 1991).

Alternatively, satisfaction is viewed here as a cumulative, abstract construct that describes customers' total consumption experience with a product or service (Johnson and Fornell 1991). This conceptualization of satisfaction is more consistent with existing views in economic psychology, where satisfaction is equated with the notion of subjective well-being (Van Raaij 1981; Wärneryd 1988), and economics, where satisfaction goes beyond expected utility to encompass postpurchase consumption utility (Meeks 1984). Satisfaction, in this view, is not a transient perception of how happy a customer is with a product or service at any given point in time. It is a customer's overall evaluation of his or her purchase and consumption experience to date. Because this cumulative satisfaction directly affects customer loyalty and subsequent profitability, it serves as a common denominator for describing differences across firms and industries. In sum, while a transaction-specific view of satisfaction provides valuable insight into particular, short-run product or service encounters, cumulative satisfaction is a fundamental indicator of a market's (or firm's) current and long-run performance. Again, this is why cumulative satisfaction is of such great interest to management.

\section{Antecedents of Market Satisfaction}

The expansive behavioral literature on satisfaction has focused on individual-level satisfaction and its psychological antecedents. Relatively few studies examine market-level satisfaction, where aggregate satisfaction with a product or service is the focus of interest. Typically, satisfaction is modeled as having one or more of the following antecedents: performance, expectation, and disconfirmation (Anderson and Sullivan 1993; Churchill and Surprenant 1982; Yi 1991).

Performance Effect. Performance here refers to the customers' perceived level of product quality relative to the price they pay (i.e., quality per dollar, or value). Specifically, how much do customers perceive to be getting relative to what they are giving up? A performance effect is consistent with Westbrook and Reilly's (1983) hypothesis of a value-percept disparity. This effect posits that satisfaction is a general psychological phenomenon that is driven primarily by the evaluation of customers' experiences in connection with a product or service. A positive (or negative) appraisal of the product's or service's ability to fulfill certain needs, wants, or desires that customers value should result in higher (or lower) satisfaction. For example, in a marketing context, Churchill and Surprenant (1982) found that satisfaction with a durable good (video disc player) could be explained simply by how well the product performed. This is consistent with more recent studies that support a direct performance effect (Anderson and Sullivan 1993; Cronin and Taylor 1992; Fornell 1992).

Prior studies have operationalized performance using both attribute-specific and global ratings of product quality (e.g., Churchill and Surprenant 1982; Westbrook and Reilly 1983). These studies typically analyze satisfaction, however, within the context of particular product or service categories (e.g., video disc players or automobiles), where common attribute-specific ratings are possible. In contrast, we compare performance and satisfaction ratings across a wide range of product and service categories that are noncomparable at an attribute-specific level. We use customers' perceptions of value, where value is the ratio of benefits received relative to costs incurred, to measure performance in a way that makes these very different products and services comparable (Johnson 1984).

Using value as a normalized measure of performance also controls for differences in budget and income constraints across individuals and households (Hauser and Shugan 1983; Lancaster 1971) and further facilitates the comparability of our measure. Finally, a direct effect of perceived performance measured as "value" is consistent with basic marketing and economic principles. In marketing, practitioners strive to provide consumers with desired product or service benefits, while in economics, households are viewed as striving to maximize desired product or service characteristics per dollar (Lancaster 1971). Perceived performance or value should, therefore, be an important predictor of marketlevel or cross-category satisfaction.

Expectation Effect. Expectations capture customers' existing attitudes or beliefs regarding expected levels of performance. These expectations should have a direct effect on individual as well as market satisfaction. Oliver (1980) argues that individual expectations serve as an anchor or standard in the evaluation of satisfaction such that perceptions are sustained in the vicinity of the anchor. Thus, expectations should have a positive impact on satisfaction. At a market level, aggregate expectations also serve as an anchor for market-level satisfaction be- 
cause they contain important information regarding a product's or a firm's past and probable future performance levels (Vanden Abeele 1988; Van Raaij 1989). As market expectations forecast a firm's ability to provide future performance, these expectations should affect satisfaction. In our example of the American automobile industry, it took some time for market expectations to adapt to the improved quality of U.S. autos. In the meantime, because expectations differed, there were nearly identical cars available with foreign and domestic nameplates (e.g., Mitsubishi and Chrysler, Ford and Mazda) that received different satisfaction ratings.

This market expectation effect is consistent with our conceptualization of satisfaction as a cumulative construct. Accordingly, satisfaction should be affected by more recent performance experiences as well as accumulated experience as reflected in a market's aggregate expectation. Previous research using the SCSB supports this effect at both the individual (Fornell 1992) and industry (Fornell and Johnson 1993) levels. The effect also parallels the work of Katona $(1979,1980)$, who spent years demonstrating that aggregate economic expectations affect aggregate economic behavior. Katona $(1979,1980)$ showed, for example, that negative attitudes or expectations, as revealed in the Index of Consumer Sentiment, both predict and contribute to economic downturns.

Disconfirmation Effect. Using disconfirmation as an antecedent follows from the disconfirmation model (Oliver 1977, 1980; Westbrook and Reilly 1983), in which the principal determinant of individual-level satisfaction is the degree to which perceived performance confirms or disconfirms performance expectations. Accordingly, when performance exceeds expectations (positive disconfirmation), satisfaction increases. When expectations exceed performance (negative disconfirmation), satisfaction decreases. Strictly speaking, the disconfirmation model predicts that satisfaction should increase with performance and decrease with expectations.

The disconfirmation model is problematic in the context of aggregate market satisfaction. One reason is that performance and expectations must be relatively independent for disconfirmation to occur. This is an unlikely condition for an entire market in which expectations, whether adaptive or rational, are relatively accurate or consistent with performance (Johnson and Fornell 1991). As long as a market has had some time to adapt and learn what levels of performance to expect, significant disconfirmation is unlikely. Aggregate disconfirmation requires an entire market of buyers to hold systematically inaccurate expectations, which must be the exception rather than the rule. One case in which this may be possible is when a market undergoes a major and unexpected change, as when a revolutionary product or service is suddenly introduced that exceeds per- formance expectations for the category. Imagine if an automobile manufacturer suddenly were to announce the availability of an electric car that holds six adults and has a 1,000-mile driving range.

A second reason that the disconfirmation model may not be appropriate for explaining aggregate market satisfaction is that market satisfaction is conceptualized as a cumulative rather than a transaction-specific evaluation. From transaction to transaction in the case of services or from use occasion to use occasion for products, one would expect some variation between performance and expectations. Service providers have a particularly difficult task in "conforming to specifications" on any particular occasion because their production process involves the largely human resources of the firm and customers themselves (Fornell and Johnson 1993). This creates a significant degree of transaction-specific uncertainty in the service production process. In contrast, customers' recent accumulation of experiences (e.g., communications or banking service over the past year) are easier to predict. Thus disconfirmation, when it occurs, is more likely when satisfaction is studied from a transaction-specific than a cumulative perspective.

However, even in a transaction-specific context, recent research suggests that disconfirmation is not as important as the direct effects of performance (Yi 1991). Cronin and Taylor (1992) directly compared alternative conceptualizations of service satisfaction using banks, pest control vendors, dry cleaning chains, and fast food outlets as stimuli. They examined whether variation in perceived service quality was a direct function of performance or driven by a disconfirmation effect (performance minus expectations) and whether satisfaction was best viewed as an outcome or antecedent of service quality. Their results support treating service quality as a direct function of performance rather than disconfirmation. They also support a causal relationship in which service quality is an antecedent to satisfaction, which, in turn, affects purchase intentions.

\section{Market-Level Model Specifications}

Our discussion suggests a parsimonious market-level model in which satisfaction is a positive function of performance and expectations. This is consistent with Van Raaij's (1981) general model of economic psychology, in which subjective well-being (i.e., satisfaction) is a direct function of firm-level behavior (i.e., performance) and perceptions of economic conditions (i.e., expectations). A fully specified formulation of this model is as follows:

$$
S_{t}=b_{0}+b_{1} \text { Perf }_{t}+b_{2} E_{t}+\text { Trend }+n_{t},
$$

where $S_{t}$ is satisfaction in time period $t$, Perf $t$ is performance in time period $t$, and $E_{t}$ is expected performance in time period $t$, Trend is a standard trend factor (Kalwani et al. 1990; Winer 1986) to account for year-toyear changes in satisfaction, and $n_{t}$ is an independent 
and identically distributed random variable with zero mean and finite variance.

Alternatively, given that we view satisfaction as a cumulative construct, it may be appropriate to model satisfaction, like expectations, as persisting over time. That is, in a dynamic model of market satisfaction, current satisfaction should be a direct function of past satisfaction. Thus, in addition to the above specification, we test a model in which satisfaction in time period $t$ is a function of performance and expectations in time pe$\operatorname{riod} t$ as well as satisfaction in time period $t-1$ :

$$
S_{t}=b_{0}+b_{1} \operatorname{Perf}_{t}+b_{2} E_{t}+b_{3} S_{t-1}+\text { Trend }+n_{t} .
$$

While consistent with our cumulative conceptualization of satisfaction, this lagged specification also helps account for heterogeneity in our sample of industries by formulating the system of equations to be tested as state dependent.

On the basis of our previous discussion, we expect that the expectations parameter in Equations 5 and 6, $E_{\mathrm{t}}$, has a large rational or stable component, yet it remains adaptive to changing conditions. Thus, we expect Equation 3 to be the best predictor of performance expectations, where we substitute $\operatorname{Perf}_{t}$, performance in time period $t$, for $P_{\mathrm{t}}$, price in time period $t$ :

$$
E_{t}=b_{0}+b_{1} E_{t-1}+b_{2} \operatorname{Perf}_{t-1}+\text { Trend }+n_{t} \text {, }
$$

where $b_{2}$ is now the coefficient of adaptation with the constraint that $b_{1}+b_{2}=1$. The rationality of the market expectations should be reflected in a large effect of prior expectations on current expectations $\left(b_{1}\right)$ when compared to the adaptation coefficient $\left(b_{2}\right)$.

In order to properly evaluate this expectation function, we compare it to two alternative expectation models described earlier. A performance version of Goodwin's (1947) extrapolative model (Eq. 2) provides a standard of comparison that is more biased toward immediate past performance information:

$$
E_{t}=b_{0}+b_{1} \text { Perf }_{t-1}+b_{2} \text { Perf }_{t-2}+\text { Trend }+n_{t},
$$

with the constraint that $b_{1}+b_{2}=1$. A performance version of the rational expectations hypothesis provides an unbiased (unadaptive) comparison standard. Recall that the rational expectations hypothesis can be tested by examining the significance of an adaptation effect in Equation 7. The rational expectations hypothesis predicts that past expectations should completely predict current expectations and that the adaptive coefficient of expectations $\left(b_{2}\right)$ is zero. As a result, the coefficient relating past expectations to current expectations $\left(b_{1}\right)$ should be equal to one under the hypothesis. This is equivalent to testing Cyert and DeGroot's (1974) moving average version of the rational expectations model, in which we use $E_{t-1}$ as a surrogate for past market information and test a function of the form

$$
E_{t}=b_{0}+b_{1} E_{t-1}+n_{t} \text {, }
$$

where $b_{1}$ is constrained to be equal to one (Lovell 1986).
In its strictest form, the rational expectations hypothesis also predicts that $b_{0}$ equals zero, which we consider in our Results section. ${ }^{1}$

Finally, although our discussion suggests that the disconfirmation model is problematic in the context of aggregate satisfaction, we estimated two versions of this model in which satisfaction is unlagged (Eq. 10) and lagged (Eq. 11):

$$
\begin{aligned}
& S_{t}=b_{0}+b_{1}\left(\operatorname{Perf}_{t}-E_{t}\right)+\text { Trend }+n_{t}, \\
& S_{t}=b_{0}+b_{1}\left(\operatorname{Perf}_{t}-E_{t}\right)+b_{2} S_{t-1}+\text { Trend }+n_{t} .
\end{aligned}
$$

In sum, we predict that market expectations are relatively stable, although adaptive, in the SCSB data. We also predict that performance and expectations positively affect satisfaction in any given period, while prior satisfaction affects current satisfaction across periods. These predictions are based on a market-level view of expectations and performance perceptions and a cumulative, rather than transaction-specific, conceptualization of satisfaction.

\section{EMPIRICAL TEST}

\section{Data and Analyses}

Of primary interest is the estimation of six alternative systems of equations. Expectations are modeled as extrapolative, adaptive, or rational. Satisfaction is modeled as a function either of performance and expectations or of performance, expectations, and lagged satisfaction. A three-stage least square algorithm is used to estimate the models because of simultaneity and expected correlation between the expectation and satisfaction equations.

The analysis uses market-level expectation, performance, and satisfaction indices available from the SCSB (Fornell 1992). The SCSB contacts approximately 100,000 representative Swedish customers each year by telephone. The respondents are screened to obtain a sample of customers who have experience with the products or services in the index, which results in an annual sample of approximately 25,000. Except for food products and television broadcasting, each respondent participates in an eight-minute telephone interview regarding a single product or service. The sample sizes for the industries range from approximately 250 to over 4,000 , depending on the number of competitors, with

\footnotetext{
${ }^{1}$ We also examined a variation on Muth's (1961) original model in which current performance is completely predicted by market expectations. However, rather than having current expectation predict current performance, we used expectations in $t-1$ to predict performance in $t$. Otherwise, there is an indeterminacy in our system of equations because both expectations and performance are used to explain satisfaction. We focus, however, on Eq. 9 because it is a more direct test of the rational expectations hypothesis, and our tests show that it provides superior predictions when compared to this alternative model.
} 
a sampling error that ranges from 0.6 percent to 1.5 percent at the 95 percent confidence level.

A variety of questions are used to assess the respondents' expectations, perceptions of performance, and level of satisfaction. Expectations are measured first by asking customers how well they expected the product or service to perform. Two measures are then collected to operationalize performance (perceived quality relative to price paid): a rating of how well the product or service has performed relative to how much the customer has paid and a rating of how much the customer has paid relative to how well the product or service has performed. Recall that these measures provide an operationalization of perceived performance that is comparable across categories. Finally, three measures are used to operationalize satisfaction: overall satisfaction, confirmation of expectations, and distance from the customer's hypothetical ideal product or service in the industry. These measures are used to construct indices of customers' aggregate expectations, perceived performance, and satisfaction each year for each product or service market where, again, a market is defined as an aggregation of individuals who purchase and consume a particular product offering (see Fornell 1992 for details).

Some comment is in order on our operationalization of satisfaction. Cumulative satisfaction is an inherently latent or abstract construct; any concrete rating of satisfaction is, at best, a proxy (Simon 1974). Satisfaction should, therefore, be operationalized by means of a variety of proxies that include ideal point ratings, disconfirmation ratings, and overall satisfaction ratings (Fornell 1992). Fornell's (1992) latent variable satisfaction index extracts only shared variance or that portion of the disconfirmation rating, for example, that is common to all three satisfaction measures. Thus, satisfaction is not confounded by disconfirmation. Rather, the measurement approach views satisfaction as reflected in a customer's expectation disconfirmation, ideal point comparison, and overall satisfaction rating. Nor is performance used as both an antecedent and a measure of satisfaction; only the psychological difference between perceived performance and a customer's expectation or ideal point is used to measure satisfaction. Because Fornell's (1992) performance and satisfaction indices are more direct measures of the constructs under study, they are used here to test the alternative model specifications (see Johnson and Fornell [1991] for a discussion). However, we estimated all the models in one case using the satisfaction index and in a second case using the overall satisfaction measurement variable to check for the existence of any confound between satisfaction and disconfirmation.

The validity of these measures is also supported from a nomological validity standpoint. To scientifically clarify what something is, one must specify "the laws in which it occurs" (Cronbach and Meehl 1955, p. 290). Nomological validity, a form of construct validity, is the degree to which a theoretical variable or construct behaves as it should behave within a system of related constructs, or a nomological net. The indices used here were operationalized in a broader system of equations that related performance and expectations to satisfaction, and satisfaction, in turn, to its consequences, which include customer loyalty (repurchase intentions, price tolerances) and complaining behavior. The strong support for the proposed linkages across industries (Fornell 1992) in turn supports the nomological validity of the satisfaction index.

The companies included in each industry account for approximately 70 percent of combined industry sales, and the focus is on the top-selling product or service (in kronor) for each firm. For example, Volvo's ratings are based on its 700-series automobiles, while IBM's personal computer ratings are based on its PS/2 computers. Consistent with our earlier definition of market, the firm-level observations in the SCSB data provide a market-level test or our predictions. Begun in 1989 with 28 industries, the SCSB expanded to 32 industries in 1990. Our analyses use data from 1989 to 1992. We focus on firms in those industries with more than one competitor for which all the necessary measures are available. This excludes the routinized purchase and consumption of food and beverage products, for which expectations are not measured. Monopolies were also excluded so as not to mix market- (or firm-) and industry-level data and to focus on relatively unregulated industries.

Available data include 56 product or service markets (firms) for 1989 across 17 industries and an expanded set of 83 product or service markets (firms) across 19 industries for 1990 through 1992. These markets (with the modal number of firms in parentheses) include airlines (2), automobiles manufacturers (9), business banks (5), public banks (5), clothing retailers (4), mainframe computer manufacturers (4), personal computer manufacturers (3), department stores (3), furniture retailers (3), oil companies (6), grocery stores (3), business insurance companies (4), auto insurance companies (5), life insurance companies (5), mail-order companies (4), newspapers (5), shippers (6), travel charter agencies (4), and television stations ( 3 ). ${ }^{2}$ To estimate the models, the 1989-1991 data are used as lags for the 1990-1992 data. The 27 firms for which observations are not available in the 1989 data are treated as censored. A correlation matrix of the data used in the analysis and the simple statistics for the variables are provided in the appendix.

The present study and analysis builds on recent research involving the SCSB (Anderson 1994; Anderson and Sullivan 1993; Anderson et al. 1994; Fornell 1992; Fornell and Johnson 1993; Johnson and Fornell 1991). For example, Johnson and Fornell (1991) develop a

\footnotetext{
${ }^{2}$ Television stations are unique in that two of the three stations are state supported. We estimated the models with and without these observations, and it did not affect our results.
} 
conceptual foundation for measuring and making interpersonal and intercategory comparisons of satisfaction. They argue that the primary determinants of cumulative satisfaction are performance and expectations, but they do not estimate these relationships. Fornell (1992) describes the methodology and reports on the resulting firm- and industry-level satisfaction indices for 1989-1991, using individual respondents as observations. His market-level expectation, performance, and satisfaction latent variable indices serve as the input for our analyses. Anderson and Sullivan (1993) also use the individual-level observations to examine the antecedents and consequences of satisfaction for firms. Their results support a direct performance effect, a small disconfirmation effect, and a marginal expectation effect. More similar to the present study, Fornell and Johnson's (1993) analysis uses industry-level SCSB data (the level of observation being an industry rather than a particular product or service market) to focus explicitly on the effects of differentiation on industry-level performance and satisfaction. They find that customers expect more and obtain higher performance levels from more differentiated industries and that expectations and performance have direct positive effects on industry-level satisfaction. Finally, Anderson et al. (1994) use firmlevel data to examine the positive effect of satisfaction on profitability and the relation of both to market share.

In contrast, the present study and analysis focus on the nature of aggregate, market-level expectations and satisfaction. Rather than presuming a particular specification, we directly test competing extrapolative, adaptive, and rational performance expectation models. We also examine the stability of market-level satisfaction over time.

\section{Results}

The three-stage least square estimates are provided in Table 1. The upper half of Table 1 shows the output for extrapolative, adaptive, and rational expectations models for which satisfaction is a function of current expectations and performance. The lower half presents the adaptive and rational expectations models for which satisfaction is a function of performance, expectations, and lagged satisfaction. ${ }^{3}$ Two statistics are provided to evaluate each system of equations, the system-weighted $R^{2}$ and the system-weighted mean square error (MSE). The single-equation or two-stage least square $R^{2} \mathrm{~s}$ are also provided.

Notice that for the unlagged satisfaction models, the adaptive expectations and rational expectations models

\footnotetext{
${ }^{3}$ The extrapolative model with lagged satisfaction is not presented in Table 1 because it provides spurious results (system-weighted $R^{2}$ and MSE values of 0.189 and 2.105 and single-equation $R^{2}$ values of 0.237 and 0.071 for expectations and satisfaction, respectively) due to the high degree of multicollinearity between lagged satisfaction and lagged performance perceptions, which is problematic in this case because expectations are only a function of lagged performance.
}

TABLE 1

THREE-STAGE LEAST SQUARE ESTIMATES FOR MARKET EXPECTATIONS AND SATISFACTION

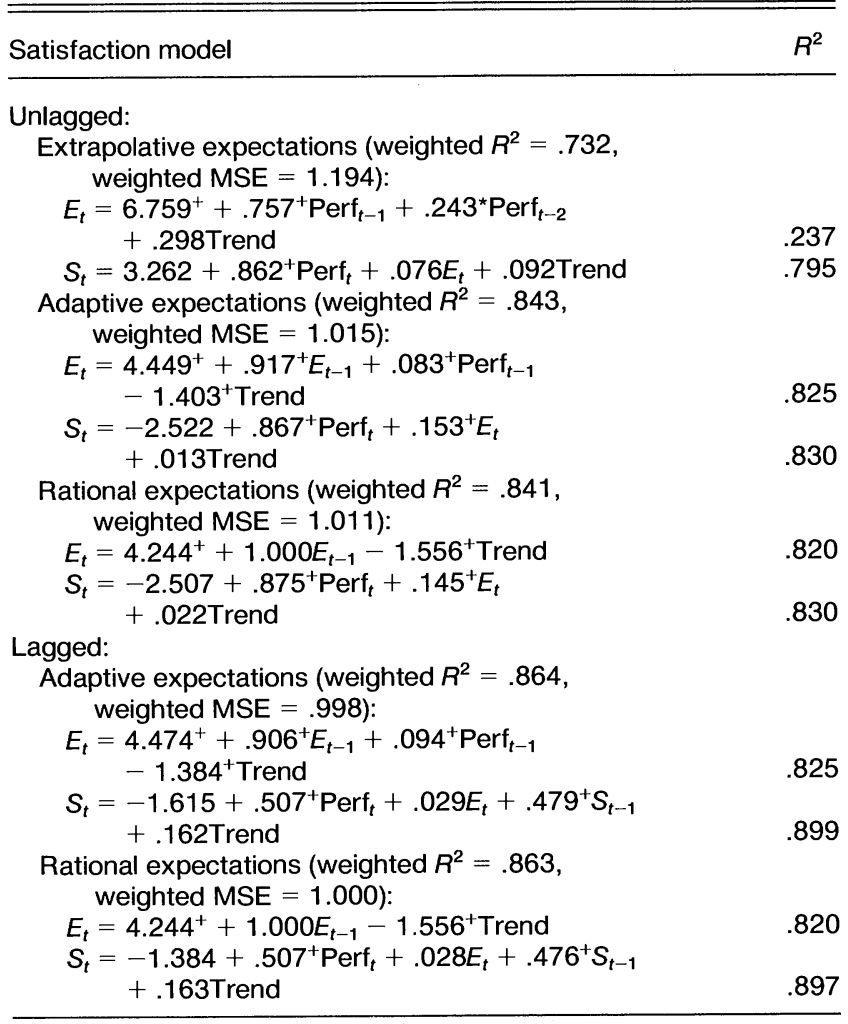

${ }^{+} p<.01$

${ }^{*} p<.05$

outperform the extrapolative model; the $R^{2}$ measure is lower for extrapolative expectations, while the MSE measure is higher. Although an extrapolative model may describe individual-level expectations (Johnson and Plott 1989; Winer 1986), market performance expectations are not well described by means of this economically biased expectations function.

Both the adaptive and rational models explain a large portion of variation in the data. The $R^{2}$ measures marginally favor the adaptive model for both the unlagged and lagged satisfaction model specifications, while the system-weighted MSE favors the adaptive model when satisfaction is lagged, but not when it is unlagged. Following Lovell (1986), we tested the adaptive model against the rational model by comparing the adaptive model (where $b_{1}+b_{2}=1$ ) to a version in which $b_{1}=1$ and $b_{2}=0$ (i.e., the rational model) as well as to a "strict" version of rational expectations in which $b_{1}=1$, $b_{2}=0$, and $b_{0}=0$. The adaptive model fit significantly better than both versions of the rational model for unlagged satisfaction $(F(1,489)=6.769, p<.01$; and $F(2,489)=40.731, p<.001$, respectively) as well as for lagged satisfaction $(F(1,488)=8.684, p<.005$; and $F(2,488)=42.323, p<.0001$, respectively). And in 
each case the adaptive coefficient is significant (see Table 1). Thus, the data support the existence of adaptive market performance expectations. However, the relatively good fit of the rational model and the relatively large coefficient on prior expectations versus prior performance in the adaptive model (.917 vs. .083 for the unlagged satisfaction model and .906 vs. .094 for the lagged model) clearly demonstrate that there is a large rational component to these expectations; market expectations are relatively stable from period to period.

It is interesting to first examine the unlagged adaptive and rational satisfaction models and then compare them to the lagged versions. When satisfaction is modeled only as a function of performance and expectation, performance has a large and significant effect on satisfaction, while expectation has a smaller, although significant, effect on satisfaction for both the adaptive and rational models. The large performance effects are consistent with the notion that satisfaction is driven primarily by an evaluation of the degree to which products and services provide desired customer benefits or value. The significant expectation effects are consistent with our view of market satisfaction as a cumulative construct. Accordingly, all past performance information, not just recent performance experiences, provides customers with relevant information that affects satisfaction.

The inclusion of lagged satisfaction results in improved $R^{2}$ and MSE values for both the adaptive and rational models. In both cases, adding lagged satisfaction significantly improves our ability to explain current satisfaction $(F(1,488)=178.089, p<.0001$ for the adaptive models and $F(1,489)=174.138, p<.0001$ for the rational models). Its effect is comparable to that of current performance (.479 vs. .507 for adaptive expectations and .476 vs. .507 for rational expectations). Although the coefficients for expectation drop to a nonsignificant level, this result should be evaluated in light of the unlagged models, where the expectation effects are significant. As we have argued, expectations reflect past market performance information that may not be reflected in current performance. The expectation models demonstrate that expectations are very stable ( $E_{t}$ is primarily a function of $E_{t-1}$ ). Therefore, including lagged satisfaction in the model effectively incorporates both lagged expectations and lagged performance. It is not surprising that current expectations add relatively little explanatory power to the lagged model. Expectations have their effect via lagged satisfaction. It is important that the lagged model demonstrates market satisfaction itself to be a relatively stable phenomena in that there are large carryover effects from period to period.

We also estimated the models using the overall satisfaction rating to operationalize satisfaction, rather than using the satisfaction index, in order to check for a possible confound between the index and disconfirmation. The results were almost identical as a result of the high correlation between the satisfaction index and the overall satisfaction rating $(r=.98)$. This supports our contention that the satisfaction index is not confounded by disconfirmation. We also estimated disconfirmation versions of our unlagged and lagged satisfaction models using Equations 10 and 11. As expected, these results (not presented) show that the disconfirmation models are dominated in every case by the models in which satisfaction is a positive function of both performance and expectations. When satisfaction is unlagged, for example, the $R^{2} \mathrm{~s}$ for the satisfaction equations are only $.154, .078$, and .077 for the extrapolative, adaptive, and rational expectations models, respectively.

\section{DISCUSSION}

Previous studies and models provide a predominantly individual-level view of the antecedents of customer satisfaction. Modeling market satisfaction requires a conceptually different view of expectations, product performance perceptions, and subsequent satisfaction. Drawing on economic psychology and economic perspectives, we develop an approach that links marketlevel expectations, performance, and satisfaction from period to period. The approach posits direct effects of expectations, performance, and prior satisfaction on current satisfaction and argues that market-level expectations are largely rational, although adaptive to changing market conditions.

Although our results may be unique to Swedish customers, previous research suggests that this is unlikely. Wikström (1983), for example, used Swedish customers to replicate a U.S.-based study by Andreasen and Best (1977) that examined satisfaction and dissatisfaction across a range of product and service categories. The pattern of results for the Swedes mirrored that of their U.S. counterparts. A recent pilot test for the American Customer Satisfaction Index, the U.S. counterpart to the SCSB, conducted for the American Society for Quality Control, also reveals similar satisfaction index levels for Swedish and U.S. buyers. Another potential limitation is that the SCSB is the result of a cross-sectional annual survey that necessitates a retrospective assessment of performance expectations. That is, customers are asked to rate how well they expected the product or service to perform. While this may create some bias in the expectation measure, the research to date supports the reliability of this measure and its use in isolating a separate expectations construct. Finally, a single survey method is used to collect all of the variable measures. The potential for method variance may systematically inflate or deflate the correlations among our variables. This suggests two important directions for future research on market-level satisfaction. One is to collect an expectation measure in a longitudinal fashion, from the same sample, prior to collecting performance and satisfaction measures. The second is to 
use alternative methods and measures in an attempt to replicate our results.

Most important is that our results add to existing bodies of knowledge involving both satisfaction and expectations. We find that market performance expectations in Sweden are adaptive. Like many countries, Sweden is experiencing fundamental changes in its economy. As shown by previous research on price expectations, there is a large rational component to observed market performance expectations. However, in contrast to previous price studies, there is a significant adaptive component to these aggregate expectations. Unlike price, some performance information is revealed only through experience (e.g., product durability), so that markets adapt to quality levels both during and after periods of change.

We also find that, in any given period, satisfaction is positively affected by both performance and expectations. Performance effects reflect the impact that recent experiences with a product or service have on satisfaction, while expectation effects reflect the impact that past performance information has on satisfaction. The demonstrated effect of market-level expectations on satisfaction is important. It refutes the idea that customers' expectations are only idiosyncratic variables that exert a random, self-canceling effect on market evaluations and behavior (Vanden Abeele 1988). This parallels macroexpectation effects found in other domains (Katona 1979) and underscores the importance of both psychological and economic perspectives in explaining market-level attitudes and behavior.

Finally, the results show that there is a significant carryover effect for customer satisfaction from period to period. That is, market satisfaction is a relatively stable, cumulative phenomena that changes gradually over time. This suggests that managers who are interested in increasing market satisfaction in order to improve future profitability should invest in long-run quality improvement programs and strategies. Shortrun tactics that temporarily increase performance or benefits per customer dollar spent will have little longrun impact.

\section{APPENDIX}

TABLE A1

CORRELATION MATRIX AND SIMPLE STATISTICS FOR SCSB DATA

\begin{tabular}{|c|c|c|c|c|c|c|c|c|}
\hline & $E_{t}$ & $E_{t-1}$ & Perf $_{t}$ & Perf $_{t-1}$ & Perf $_{t-2}$ & $S_{t}$ & $S_{t-1}$ & Trend \\
\hline$E_{\mathrm{t}}$ & 1.000 & & & & & & & \\
\hline$E_{t-1}$ & .902 & 1.000 & & & & & & \\
\hline Perf & .570 & .561 & 1.000 & & & & & \\
\hline Perf $_{t-1}$ & .594 & .637 & .871 & 1.000 & & & & \\
\hline Perf & .539 & .591 & .826 & .879 & 1.000 & & & \\
\hline$S_{t}$ & .607 & .608 & .904 & .822 & .794 & 1.000 & & \\
\hline$S_{t-1}$ & .600 & .635 & .828 & .905 & .832 & .907 & 1.000 & \\
\hline Trend & .122 & .286 & -.005 & .094 & .079 & .017 & -.008 & 1.000 \\
\hline$N$ & 248 & 221 & 248 & 222 & 139 & 248 & 222 & 249 \\
\hline $\bar{x}$ & 72.851 & 71.719 & 65.823 & 65.583 & 65.229 & 65.675 & 65.857 & 2.000 \\
\hline SD & 6.903 & 7.390 & 6.278 & 6.551 & 6.874 & 6.739 & 7.155 & .818 \\
\hline
\end{tabular}

[Received September 1992. Revised July 1994. Kent B. Monroe and Brian Sternthal served as editors and Russell S. Winer served as associate editor for this article.]

\section{REFERENCES}

Anderson, Eugene W. (1994), "Cross-Category Variation in Customer Satisfaction and Repurchase," Marketing Letters, 5 (January), 19-30.

- and Claes Fornell (1993), "A Customer Satisfaction Research Prospectus," in Service Quality: New Directions in Theory and Practice, ed. Richard L. Oliver and Roland T. Rust, Newbury Park, CA: Sage, 239-266.

, Claes Fornell, and Donald R. Lehmann (1994), "Customer Satisfaction, Market Share, and Profitability: Findings from Sweden," Journal of Marketing, 58 (July), 53-66. and Mary Sullivan (1993), "The Antecedents and Consequences of Customer Satisfaction for Firms," Marketing Science, 12 (Spring), 125-143.

Andreasen, Alan R. and Arthur Best (1977), "Consumers Complain - Does Business Respond?" Harvard Business Review, 45 (July-August), 93-101.

Bitner, Mary Jo (1990), "Evaluating Service Encounters: The Effects of Physical Surroundings and Employee Responses," Journal of Marketing, 54 (April), 69-82.

Bolton, Ruth N. and James H. Drew (1991), "A Multistage Model of Customers' Assessments of Service Quality and Value," Journal of Consumer Research, 17 (March), 375384.

Boulding, William, Richard Staelin, Ajay Kalra, and Valerie Zeithaml (1993), "A Dynamic Process Model of Service Quality: From Expectations to Behavioral Intentions," Journal of Marketing Research, 30 (February), 7-27.

Churchill, Gilbert A. and Carol Surprenant (1982), "An Investigation into the Determinants of Customer Satisfac- 
tion," Journal of Marketing Research, 19 (November), 491-504.

Cronbach, L. J. and Paul E. Meehl (1955), “Construct Validity in Psychological Tests," Psychological Bulletin, 52 (March), 281-302.

Cronin, J. Joseph, Jr. and Steven A. Taylor (1992), "Measuring Service Quality: A Reexamination and Extension," Journal of Marketing, 56 (July), 55-68.

Cyert, Richard M. and Morris H. DeGroot (1974), "Rational Expectations and Bayesian Analysis," Journal of Political Economy, 82 (June), 521-536.

Darby, Michael R. and Edi Karni (1973), "Free Competition and the Optimal Amount of Fraud," Journal of Law and Economics, 16 (April), 67-88.

Della Bitta, Albert J. and Kent B. Monroe (1974), “The Influence of Adaptation Level on Selective Price Perceptions," in Advances in Consumer Research, Vol. 1, ed. Scott Ward and Peter Wright, Ann Arbor, MI: Association for Consumer Research, 359-369.

Epstein, Seymour (1979), "The Stability of Behavior. I. On Predicting Most of the People Much of the Time," Journal of Personality and Social Psychology, 37 (December), 1097-1126.

(1980), "The Stability of Behavior. II. Implications for Psychological Research," American Psychologist, 35 (September), 790-806.

Fornell, Claes (1992), "A National Customer Satisfaction Barometer: The Swedish Experience," Journal of Marketing, 56 (January), 6-21.

and Michael D. Johnson (1993), "Differentiation as a Basis for Explaining Customer Satisfaction across Industries," Journal of Economic Psychology, 14 (December), 681-696.

Glazer, Rashi, Joel H. Steckel, and Russell S. Winer (1988), "The Formation of Key Marketing Variable Expectations and Their Impact on Firm Performance: Some Experimental Evidence," Marketing Science, 8 (Winter), 1834.

, Joel H. Steckel, and Russell S. Winer (1990), "Judgmental Forecasts in a Competitive Environment: Rational vs. Adaptive Expectations," International Journal of Forecasting, 6 (July), 149-162.

Goodwin, R. M. (1947), “Dynamical Coupling with Especial Reference to Markets Having Production Lags," Econometrica, 15 (July), 181-204.

Hauser, John R. and Steven M. Shugan (1983), "Defensive Marketing Strategies," Marketing Science, 2 (Fall), 319 360.

Hicks, J. R. (1939), Value and Capital, London: Oxford University Press.

Hirsch, Albert and Michael Lovell (1969), Sales Anticipations and Inventory Behavior, New York: Wiley.

Jacobson, Robert D. and Carl Obermiller (1990), "The Formation of Expected Future Price: A Reference Price for Forward-Looking Consumers," Journal of Consumer Research, 16 (March), 420-432.

Johnson, Michael D. (1984), "Consumer Choice Strategies for Comparing Noncomparable Alternatives," Journal of Consumer Research, 11 (December), 741-753.

- and Claes Fornell (1991), "A Framework for Comparing Customer Satisfaction across Individuals and Product Categories," Journal of Economic Psychology, 12 (June), 267-286. and Charles R. Plott (1989), "The Effect of Two Trading Institutions on Price Expectations and the Stability of Supply-Response Lag Markets," Journal of Economic Psychology, 10 (June), 189-216.

Kalwani, Manohar U., Chi Kin Yim, Heikki J. Rinne, and Yoshi Sugita (1990), "A Price Expectations Model of Customer Brand Choice," Journal of Marketing Research, 27 (August), 251-262.

Katona, George (1979), "Toward a Macropsychology," American Psychologist, 34 (February), 118-126.

(1980), Essays on Behavioral Economics, Ann Arbor: University of Michigan, Institute for Social Research.

Lancaster, Kelvin (1971), Consumer Demand: A New Approach, New York: Columbia University Press.

Lovell, Michael C. (1986), "Tests of the Rational Expectations Hypothesis," American Economic Review, 76 (March), 110-124.

Mansfield, Edwin (1975), Microeconomics: Theory and Applications, New York: Norton.

Meeks, J. G. Tulip (1984), "Utility in Economics: A Survey of the Literature," in Surveying Subjective Phenomena, Vol. 2, ed. Charles F. Turner and Elizabeth Martin, New York: Sage, 41-91.

Monroe, Kent B., Albert J. Della Bitta, and Susan L. Downey (1977), "Contextual Influences on Subjective Price Perceptions," Journal of Business Research, 5 (December), 277-291.

Muth, John F. (1961), "Rational Expectations and the Theory of Price Movements," Econometrica, 29 (July), 315-335.

Nelson, Philip (1970), "Information and Consumer Behavior," Journal of Political Economy, 78 (March/April), 311-329.

Nerlove, Marc (1958), “Adaptive Expectations and Cobweb Phenomena," Quarterly Journal of Economics, 73 (May), 227-240.

Oliver, Richard L. (1977), "Effect of Expectation and Disconfirmation on Post-exposure Product Evaluations: An Alternative Interpretation," Journal of Applied Psychology, 62 (April), 480-486.

(1980), "A Cognitive Model of the Antecedents and Consequences of Satisfaction Decisions," Journal of Marketing Research, 17 (November), 460-469.

- and Russell S. Winer (1987), "A Framework for the Formation and Structure of Consumer Expectations: Review and Propositions," Journal of Economic Psychology, 8 (September), 469-499.

Parasuraman, A., Valerie A. Zeithaml, and Leonard L. Berry (1988), "SERVQUAL: A Multiple-Item Scale for Measuring Consumer Perceptions of Service," Journal of Retailing, 64 (Spring), 12-40.

Pashigian, B. Peter (1970), "Rational Expectations and the Cobweb Theory," Journal of Political Economy, 78 (4), 338-352.

Plott, Charles R. (1986), "Rational Choice in Experimental Markets," in Rational Choice: The Contrast between Economics and Psychology, ed. R. Hogarth and M. Reder, Chicago: University of Chicago Press, 117-143.

Simon, Herbert A. (1979), "Behavioral Research: Theory and Public Policy," in The 1979 Founders Symposium, The Institute for Social Research: Honoring George Katona, Ann Arbor, MI: Institute for Social Research, 11-35.

Simon, John L. (1974), "Interpersonal Comparisons of Welfare Can Be Made-and Used for Redistribution Decisions," Kyklos, 27 (January), 63-98. 
Strumpel, Burkhard (1979), "The Role of Behavioral Research," The 1979 Founders Symposium, The Institute for Social Research: Honoring George Katona, Ann Arbor, MI: Institute for Social Research, 51-59.

Tversky, Amos and Daniel Kahneman (1974), "Judgment under Uncertainty: Heuristics and Biases," Science, 185 (September 27), 1124-1131.

Vanden Abeele, Piet (1988), "Economic Agents' Expectations in a Psychological Perspective," in Handbook of Economic Psychology, ed, W. Fred Van Raaij, Gery M. Van Veldhoven, and Karl-Erik Wärneryd, Dordrecht: Kluwer, 478-515.

Van Raaij, W. Fred (1981), “Economic Psychology," Journal of Economic Psychology, 1 (March), 1-24.

- (1989), "Economic News, Expectations, and Macroeconomic Behavior," Journal of Economic Psychology, 10 (December), 473-493.

Wärneryd, Karl-Erik (1988), "Economic Psychology as a Field of Study," in Handbook of Economic Psychology, ed. W. Fred Van Raaij, Gery M. Van Veldhoven, and Karl-Erik Wärneryd, Dordrecht: Kluwer, 2-41.
Westbrook, Robert A. and Michael D. Reilly (1983), "ValuePercept Disparity: An Alternative to the Disconfirmation of Expectations Theory of Consumer Satisfaction," in Advances in Consumer Research, ed. Richard P. Bagozzi and Alice M. Tybout, Vol. 10, Ann Arbor, MI: Association for Consumer Research, 256-261.

Wikström, Solveig (1983), "Another Look at Consumer Dissatisfaction as a Measure of Market Performance," Journal of Consumer Policy, 6 (1), 19-35.

Williams, Arlington W. (1987), "The Formation of Price Forecasts in Experimental Markets," Journal of Money, Credit, and Banking, 19 (February), 1-18.

Winer, Russell S. (1985), "A Price Vector Model of Demand for Consumer Durables: Preliminary Developments," Marketing Science, 4 (Winter), 74-90.

(1986), "A Reference Price Model of Brand Choice for Frequently Purchased Products," Journal of Consumer Research, 13 (September), 250-256.

Yi, Youjae (1991), "A Critical Review of Customer Satisfaction," in Review of Marketing 1990, ed. Valerie A. Zeithaml, Chicago: American Marketing Association, 68123. 